\title{
Link Between Employee Voice and Organizational Citizenship Behavior: Moderating Role of Psychological Safety
}

\author{
KAZIM SALMAN \\ Deputy Director, MSW Establishment Division, GoP Islamabad. \\ Email: skazim.salman@gmail.com \\ Tel: $0333-5744618$ \\ Dr. SAJID HUSSAIN AWAN \\ Assistant Professor, Foundation University Rawalpindi. \\ Email: drsajid.hussain@fui.edu.pk \\ Tel: 0334-5494121 \\ Dr. NAZIA HABIB \\ Assistant Professor, Fatima Jinnah Women University, Rawalpindi. \\ Email: naziahchaudary@gmail.com \\ Tel: 0316-0520891
}

\begin{abstract}
Speaking up at the workplace has a double-edged sword effect. This effect is dependent on the context and the ways an individual raises voice. The current study finds that an employee's voice contributes to organizational citizenship behavior, especially when employees feel psychologically safe. In this context, three dimensions of employees' voice behavior were examined including supervisor-subordinate relationship, employee job satisfaction, and employee motivation that enhance organizational citizenship behavior. Additionally, the research also explores the moderating role of psychological safety that strengthens the relationship between employees' voice and organizational citizenship behavior. Data collected from 361 employees using a survey technique, revealed that employees'voice has a positive and significant impact on organizational citizenship behavior. It was also found that psychological safety significantly moderates the relationship between employee voice and organizational citizenship behavior. This study positively contributes to voice and organizational citizenship literature. The study suggests that organizations should encourage employees' voice behavior and nurture a psychologically safe environment to improve organizational citizenship behavior among employees. This study also discusses the theoretical and practical implications of voice behavior and how it leads to organizational citizenship behavior.
\end{abstract}

Keywords: Employees Voice Behavior, Psychological Safety, Organizational Citizenship Behavior.

\section{Introduction}

Encouraging employee voice is considered as one of the important factors to achieve employee motivation and engagement. It ensures employee participation from planning to decision making in contemporary organizational processes. The extant research emphasizes the importance of an open communication system for organizations to sustain and succeed in a dynamic business competition (Jha et al., 2019; Ruck et al., 2017; Cheng et al., 2013; Qi et al., 2014). The majority of researchers argue that employees' upward communication in terms of suggestions, ideas, and information about problems or issues of concern, have unique implications for employee performance and their association with their organization. Such a system 
helps the managers to respond appropriately to dynamic business situations and make effective decisions based on realistic problem identification and solving approaches.

Researchers (Bienefeld \& Grote, 2012; Ashford, Sutcliffe, \& Christianson, 2009) have also indicated that employees are often reluctant to share important information with their managers, subordinates, and even with their teammates in parallel positions. This situation is more visible in public sector organizations of developing countries, where a culture of sharing knowledge and information is not well established. Since the democratic norms are not well recognized in these developing countries therefore, the supervisors/managers do not encourage their employees to participate or give their opinions on improving the organizational policies and procedures. Especially they are not allowed to raise the issues or concerns relating to their organization. Another reason for such a gap could be the power distance between employees and their supervisor, which is fairly high in traditional bureaucratic structures of public sector organizations (Hober, Schaarschmidt, \& von Korflesch, 2019; Adegbaju, 2018; Milosevic, 2017). This kind of power distance leads to the feeling of insecurity for raising their voice, hence they are reluctant to speak up (Lin et al., 2019).

On the other hand, a sense of security encourages employees to share their ideas and concerns, which positively contributes to improvement in overall organizational effectiveness (Edmondson, 1999). Researchers have also shown the importance of voice behavior in employees' commitment and citizenship behavior. Butler and Whiting (2019) explain the process through which voice can lead to betterment in employees' behavior and performance. According to them, most of the time the employees have a better understanding and knowledge about organizational functioning in comparison to their managers. Therefore, these employees should be given equal opportunity to raise their voice and participate in related decision making which can lead to an improvement in their personal as well as organizational performance. In this backdrop, the current study was designed to explore the effectiveness of voice on organizational citizenship behavior in the presence of psychological safety (PS) in public sector organizations of Pakistan.

Recent research has witnessed a growing interest in the causes and effects of voice behavior in organizations. It is important mainly because voice behavior provides an opportunity for employees to speak about structural flaws and systemic failures well before time (Botero \& Dyne, 2009). Hence, any organization must provide avenues to its employees for sharing their viewpoints about the norms and practices in the organization (Garner \& Garner, 2011). Given the importance of the organizational voice, we have chosen federal government organizations of Pakistan, formally termed as ministries and divisions. These organizations are responsible to make critical decisions, implement the government policies, conduct research on available data, and monitor and control the entire bureaucracy of the country. Therefore, encouraging employees' voice to provide innovative ideas and valuing their opinion in critical decision making becomes important to improve the effectiveness and performance of such organizations (Kalia, 2013).

\section{Significance of the Study}

The role of organizational voice is to give prior insight through the constructive and valuable input from employees of an organization before happening of any unforeseen and undesirable incident, which negatively affects its customers (Janssen \& Gao, 2015). Although previous research on the organizational voice has studied it in the context of psychological and organizational behavior, yet several issues and underlying concepts remained under-studied (Whiting, Podsakoff \& Pierce, 2008). Moreover, in developing countries, the concept of organizational voice is fairly novel and remained under-researched area (Emelifeonwu \& Valk, 2018). Hence, the current study is quite significant as it answers several questions related to voice and provides insight into its dimensions. Moreover, it additionally studies the moderating impact of psychological safety on the relationship between organizational voice and organizational citizenship behavior. 
Employees' voice is one of the important factors that help to improve the functional procedures of an organization (Frandsen \& Johansen, 2018; Fast, Burris \& Bartel, 2014). Previous research has discussed its predictors and consequences to some extent, mostly as an outcome variable (Ling \& Zeyin, 2016; Wang \& Lin, 2019). In very few cases it has been studied as a mediator (Avey, Wernsing \& Palanski, 2012), which is another kind of outcome variable. However, we found very few studies on employee or organization related consequences of voice behavior. For instance, Ohana (2015) found a positive relationship between voice and team's affective commitment leading to their citizenship behavior. Similarly, Song et al. (2019) studied the relationship between promotive voice, prohibitive voice, and employee performance in Chinese culture. In another similar study by Miao, Lu, Cao, \& Du, (2020) found a significant moderating effect of psychological safety on the relationship between high-performance work practices and prohibitive voice behavior. However, we could not find any specific study with the factors that contribute to voicing and its impact on organizational citizenship behavior in the presence of psychological safety.

The available literature emphasizes on the basic theories and primary characteristics of the phenomenon (Bashshur \& Oc, 2015). In the last few years, however, an employee's voice has been given importance as a measure of organizational effectiveness as well as employees' citizenship behavior (Fast et al., 2014). However, researchers do not agree on factors contributing to employee voice behavior and suggest its exploration with multiple dimensions in different contexts and cultures. It is generally observed that the supervisor's role in promoting voice behavior is very important as employees themselves are reluctant and tend to weigh the cost-effectiveness of such behaviors while discussing something with their supervisor (Lam et al., 2018; Liang et al., 2012). Although, researchers have acknowledged the role of supervisors in employee voice behavior to some extent, they have not discussed it as a dimension of voice. Voicing is not a self-originating phenomenon; it requires motivation from the supervisor through a supervisor-subordinate relationship (Neves, 2012; Fast et al., 2014). There is also evidence that employee job satisfaction is related to the voice (Milliken et al. 2015), which may lead to organizational citizenship behavior (Cinar et al., 2013). Research has also proved that psychological safety can modify the effect of organizational voice (Newman et al., 2017; Fatima et al., 2015). Studying the moderating effect of psychological safety can provide interesting results. Recently, Ng, Dyne, and Ang (2019) also suggested studying voice behavior in the context of supervisor-subordinate relationship and psychological safety. Therefore, the main objective of the current research is to examine the relationship between employee voice and organizational citizenship behavior and explore the contingent effect of psychological safety on the relationship.

\section{Literature Review}

Organizations try to keep up with the pace of institutional changes and equip their employees with skills that contribute to organizational function (Nembhard \& Edmondson, 2011). At the same time, organizations want their employees to put forth their ideas aimed at positively contributing to organizational functioning (Edmondson, 1999). These ideas have their pros and cons. Research has shown that due to the negative consequences of voicing opinion, employees tend to be more reserved while speaking up about a problem that the organization is facing (Detert \& Burris, 2007). Research has further substantiated that if these employees feel secure about their involvement, they tend to contribute even more positively by raising their voice (Edmondson, 1999). Research also supports that psychological safety is considered as one of the key characteristics of today's' high performing organizations (Bergmann \& Schaeppi, 2016). Therefore, organizations try to find out ways and means to implement strategies and get the benefit of suggestions for continuous improvement in the functions and procedures of the organization.

\section{Employee Voice behavior}

The concept of employee voice was introduced by Hirschman (1970) but remained under-studied for a long time. However, recently with a growing focus on customer/client satisfaction, the topic has gained more attention in research and practice (McClean, 2017). The definition of voice has remained an area of key interest among organizational behavior researchers (Oreg et al., 2018). Several researchers have defined it 
as something which is always connected to the inner-self of an employee, while others have tried to define it in terms of organizational ways and means to express and point out a problem that needs rectification (Dutton et al., 2001). Based on the definition adopted or adapted, researchers have, therefore, tried to explain its dependence on inner or outer factors.

Voice habit is the spontaneous expression of suggestions, concerns, and opinions that may affect the individual, team, and organization (Wood \& Neal 2007; Ng \& Feldman, 2015). This behavior provides employees an opportunity to clearly and boldly present ideas and opinions to suggest remedies or improvements in job-related problems. This type of communication generally takes place between employee and decision-making authorities (Detert \& Burris, 2007; Tangirala \& Ramanujam, 2008). Budd, Gollan, and Wilkinson (2010) extend the domain of voice as a formal expression within and outside the organization. It is aimed at specifically mending the existing operations in an organization. An open environment that facilitates the upward communication of information, supervisor-subordinate relationship, employee performance, idealism, and real performance can lead to an enhanced level of voicing within an organization (Lapointe \& Vandenberghe, 2018). Some studies have also indicated that organizational voice can be explained through citizenship behavior, gender issues within and outside the organization, motivation, ego-centric and ego-defensiveness behavior, job security and psychological safety (Rasheed et al., 2017; Morrison, 2014; James \& Moseley, 2014; Weiss et al., 2017; Barry \& Wilkinso, 2016; Schmitt et al. 2016; Hassan et al., 2015).

Researchers theorize that human behavior is often dependent on various aspects of an individual's personality (Mulhern and Massey 2013). The relationship between employees and their supervisor plays a critical role in shaping such behavior. A good relationship between the two create a conducive environment for voice behavior. Especially when supervisors' motivate and encourage their subordinates to give their opinions, highlight issues, and concerns and provide innovative ideas to improve the procedures and work processes. Employees working with these managers feel intrinsically motivated to give honest opinions and participate in decision making. They feel as effective members of the organization and take an active part, responsibility, and ownership to improve the organizational performance and effectiveness. This type of democratic management style plays a critical role in flourishing voice behavior among employees. (Ho, 2017; Basit, 2017; Janssen \& Gao, 2015) Therefore, we considered a supervisor-subordinate relationship (SSR) as an important dimension of employee voice behavior in the present study.

Another way of analyzing the relationship between employee motivation and employee voice behavior is through upward safety communication. It is seen that motivation to raise voice increases with the increase in seniority (Chen, 2017). Employee motivation can be analyzed in two ways i.e. individual motivation and team motivation. It is seen that team citizenship can be easily predicted by team voice (Ohana, 2016). However, with the increase in intrinsic motivation, the employees of an organization are less likely to exchange their views socially (Ohana, 2016). Another aspect of employee motivation is avoidance motivation. It is seen that constructive voice increases with an increase in motivation but the defensive voice is related to avoidance motivation (Ma, 2016). Moreover, employee voice is strongly dependent upon employee motivation which leads to better workplace performance in an organization.

The relationship between employee voice and job satisfaction is also positively related (Song et al., 2018). Herzberg's two-factor theory lays the foundation of the relationship between employee voice behavior and employee job satisfaction in an organization (Alfayad \& Arif, 2017). It is also seen that direct voice promotes manager's heterogeneous decision making and thus improves employee job satisfaction (Pyman et al., 2006). Research has also shown that due to the negative consequences of voicing, employees tend to speak more about the organizational problems, than about procedures that require improvement (Detert \& Burris, 2007). Psychological also contributes to improving employee motivation and job satisfaction (Bergmann \& Schaeppi, 2016). Therefore, to make effective use of psychological safety in this technique, organizations are trying to find out ways and means to implement it so that they may get the benefit of suggestions aimed at continuous improvement in the functions and procedures of the organization. 


\section{Psychological Safety}

Psychological safety is defined as the employees' shared belief that it is safe to communicate by taking the risk, which is specifically related to the experience of feeling able to speak up with relevant ideas, questions, or concerns (Edmondson, 2018). Research has established that employees are reluctant to raise their voices as they consider silence as a safe strategy. This is specifically relevant in setups where managers exercise uninterrupted authority. Employees feel vulnerable to an obvious logic that raising voice against any issue or procedure can lead to negative consequences for them. That is the point where Psychological safety comes to rescue (Nechanska, Hughes, \& Dundon, 2020).

Miao et al. (2020) describe the characteristics of organizations with greater psychological safety as tolerant and participative. These organizations motivate their employees to express their ideas openly without any fear of being penalized for outcomes. Such organizations understand, respect, praise, and protect their employees and build trust among them to effectively participate in building common goals of interest between organizations and employees. These organizations allow employees' free expression and accept their different opinions and show concern for them. This kind of environment nurtures positive work behaviors among employees and they start owning their organizational decision more enthusiastically. On the other hand, an organization lacking psychological security creates a negative perception among employees that the organization is least concerned about their interests and is working to achieve a single motive of profit maximization (Bergmann \& Schaeppi, 2016). Consequently, employees in these organizations also exhibit a lack of interest in improving the functions or procedures of the organization. In other words, they show the lowest level of commitment and citizenship behavior with their organization. Therefore, the level of psychological safety can play a critical role in determining the strength of the relationship between employee voice and their citizenship behavior.

\section{Organizational Citizenship Behavior}

The changing dynamics of organizational behavior are helping researchers to understand its effect on employee's behavior when exposed to new situations (Dekas et al., 2013; Jain et al,. 2011). Organizational citizenship behavior has also evolved (Pierce \& Maurer, 2009). Organ (1988) suggests that organizational citizenship behavior has three main dimensions. First, it is something that is outside the original bound of what duties and roles an employee is performing. Second, it is not a reward-related behavior, and third that the organizational citizenship behavior helps organizations to achieve effectiveness. However, the definition has not further evolved since the time of Organ (1988) in the last three decades. Even today, organizational citizenship behavior is considered as optional or discretionary behavior which is neither required nor requested by the organization and the same is not honored in terms of monetary benefits (Grant \& Mayer, 2009). It is also seen that front line managers with an increase in perceived level of voice tend to be more committed to the organization and increase the work effort for the organization i.e. show organizational citizenship behavior (Heffernan \& Dundon, 2015; Farndale et al., 2011).

Based on the above discussion, we study the concept of voice with three dimensions namely, supervisorsubordinate relationships (SSR), employee motivation (EM), and employee job satisfaction (JS). Although, research has recommended SSR, EM and JS as contributing factors to encourage voice among employees, but never studied these collectively as dimensions of voice behavior (Suer \& Kecici, 2018; Kim et al., 2015; Aryee et al., 2017).

\section{Research Hypotheses and Framework}

Previous research has established a positive relationship between employee voice behavior and their commitment to their organization (Farndale et al., 2011). However, we could not find a specific study on the direct relationship between voice and organizational citizenship behavior, which is a consequence of a higher level of organizational commitment. Although Chan and Lai (2017) found a positive effect of 
communication satisfaction on employees' citizenship behavior, they also did not study the specific role of employee voice in this regard. Similarly, Kandlousi et al. (2010) reported that communication leads to positive attitudes among employees and is one of the strongest predictors of OCB. The proponents of the social exchange theory provide a good explanation for the relationship between employees' voice and citizenship behavior. Berger (2009) indicates that if employees are provided satisfactory prospects to communicate their ideas and concerns, they achieve higher quality in mutual interaction within the organization. These employees positively respond through different positive work behaviors, which are likely to be expressed in OCB. Based on the discussed literature, we develop our first proposition for the current study as:

H1: Employee voice has a positive effect on organizational citizenship behavior.

Researchers have explored psychological safety as a mediator (Spitzmuller, Van Dyne, \& Ilies 2008; Walumbwa \& Schaubroeck, 2009; Liang et al., 2012; Wu et al., 2012), especially in the context of voice behavior and supervisor-subordinate relationship. In few studies, it was taken as a predictor of innovation (Ming et al., 2015), involvement (Li \& Ling, 2010), or performance (Li \&Yan 2007; Edmondson, 2018) to some extent.

However, we have not found any specific study on the relationship between psychological safety and organizational citizenship behavior. Although researchers (Qadeer \& Jaffery, 2014) have reported a positive relationship between psychological capital and OCB, psychological safety was not studied in this context. We have used psychological safety as a moderator in the current study. Moreover, the direct relationship between psychological safety and organizational citizenship behavior is also a part of our research model. Therefore, we propose a positive relationship between the two variables and put our second hypothesis as:

H2: Psychological safety has a significant and positive effect on organizational citizenship behavior.

Researchers have found that psychological safety can alter or improve the strength of the relationship between voice and its consequences. As it is the perceived freedom in the expression of the true self, that is, whether an individual feels confident in expressing his/her opinions, ideas, concerns, and beliefs without fear of negative consequences to self-image or career prospects (Chrobot-Mason \& Aramovich, 2004). Singh et al (2013) studied the mediating relationship of psychological safety between diversity climate and organizational citizenship behavior and found significant relationships in both of its forms (organizational OCB and interpersonal OCB).

Edmonson and Lei (2014) have emphasized the importance of psychological safety as it enables the employee to share information and exchange ideas with other members of the organization in the attainment of organizational goals. In other words, they have highlighted the importance of psychological safety for employees to raise their voices for the improvement of organizational procedures. However, we have not been able to find any specific study on the moderating effect of psychological safety for the relationship between voice and OCB. Therefore, we consider it important to study this relationship and acknowledge the importance of psychological safety to improve the effectiveness of voice for OCB. In this backdrop, we make the following proposition for the current study:

H3: Psychological safety moderates the relationship between employee voice and organizational citizenship behavior.

Overall, the study was designed to examine as to what extent psychological safety moderates the relationship between voice behavior and organizational citizenship behavior, where the employee voice was measured through its dimensions i.e. supervisor-subordinate relationship, employee job satisfaction, and employee motivation. 
The proposed relationships are depicted in the following framework:

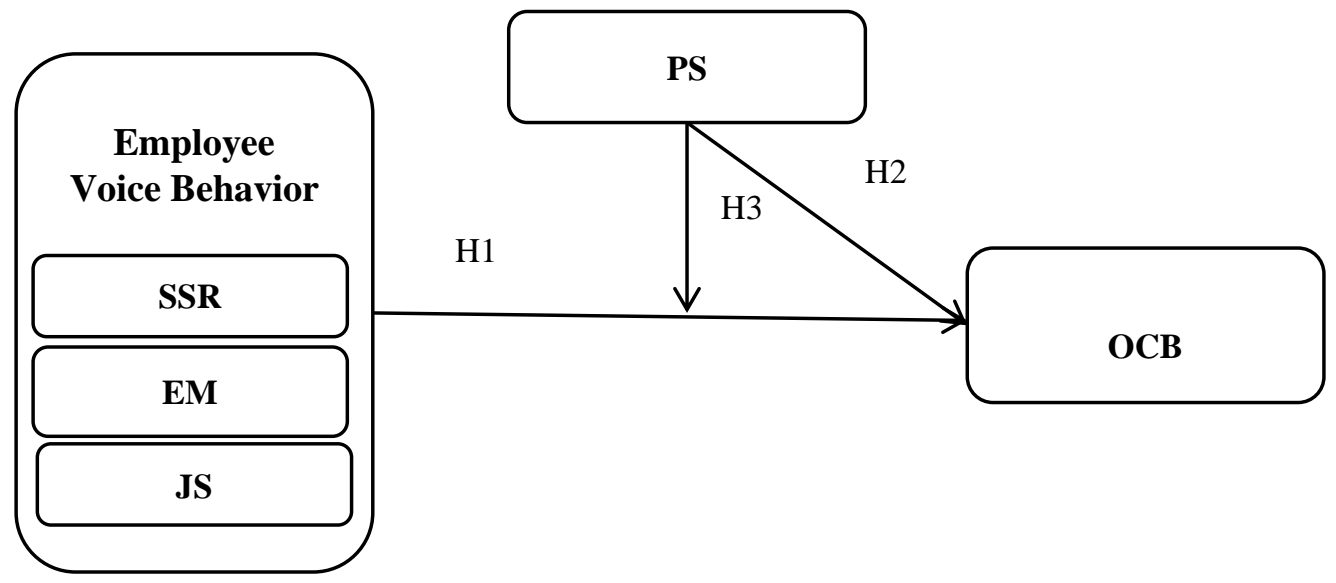

Key:

Figure 1 - Hypothesized research model

SSR: Supervisor subordinate relationship

EM: Employee motivation

JS: Job satisfaction

PS: Psychological safety

OCB: Organizational citizenshin behavior

\section{Research Methodology}

The current study adopted survey technique for which targeted organizations were ministries and divisions working directly under the federal government of Pakistan. Further sampling methodology and description are given in the next section.

\section{Sample}

The official website of the government of Pakistan indicates that there are a total of 42 ministries/divisions out of which the organizations with employee strength of more than 80 were selected. Hoti et al., (2016) have mentioned that approximately 8000 employees work in these ministries, which makes our total population for the current study. Data were collected through self-administered survey questionnaires during the period between June-December 2018. For this purpose, 450 employees were approached to participate but 370 replied showing a response rate of $82 \%$. Out of these 370 received responses, 9 were incomplete and could not be used. Remaining 361 questionnaires were used for the final analysis, which made the useful sample size for the current study. Further description of the sample is given in Table 1. As shown in the Table 1, majority of the participants (49\%) were in the age bracket between 31 to 40 years. Approximately $81 \%$ of the sample was comprised of male participants, mostly having 6 to 10 years of experience. The respondents were provided hard copies of survey questionnaires at their workplace. These were received back during 2-10 days' time period from the date of contact. To facilitate the respondents, whenever there was a query during the process of filling the questionnaire or responding to a statement of the question, it was resolved then and there. The queries were responded on phone and sometimes inperson as per the convenience of the respondent and the researcher.

\section{Measures}

The independent variable of voice was taken as a combined construct of supervisor-subordinate relationship (SSR), employee job satisfaction (EJS) and employee motivation (EM). It was measured with 
54 items, taken from three studies for each sub-dimension. SSR was measured with 16 items identified by Scarpello and Vandenberg (1987). The initial reliability coefficient of the scale, as mentioned by Scapello and Vandenberg (1987), was 0.95. The sample item was "I am satisfied with the way my supervisor sets clear work goals." Similarly, JS and EM were measured with a 20 items scale from Hirschfeld (2000) and 18 items scale form Deci and Ryan (2000), respectively. The internal consistency of these instruments, as indicated in their original studies, was 0.87 and 0.93 respectively.

Table 1 - Demographics

\begin{tabular}{|c|c|c|c|c|c|c|c|c|}
\hline & \multicolumn{7}{|c|}{ Qualification } \\
\hline & & Matric & FA/FSC & Bachelors & Masters & M.Phil. & Ph.D & Total \\
\hline \multirow[t]{2}{*}{ Gender } & Male & 1 & 18 & 47 & 183 & 40 & 2 & 291 \\
\hline & Female & 0 & 0 & 22 & 45 & 3 & 0 & 70 \\
\hline Total & & 1 & 18 & 69 & 228 & 43 & 2 & 361 \\
\hline \multirow[t]{6}{*}{ Experience } & $0-5$ & 0 & 2 & 6 & 60 & 5 & 0 & 73 \\
\hline & 6-10 & 0 & 14 & 26 & 62 & 4 & 0 & 106 \\
\hline & $11-15$ & 0 & 1 & 17 & 43 & 9 & 2 & 72 \\
\hline & $16-20$ & 0 & 0 & 12 & 35 & 6 & 0 & 53 \\
\hline & $21-25$ & 0 & 0 & 3 & 22 & 18 & 0 & 43 \\
\hline & $\begin{array}{l}26 \\
\text { above }\end{array}$ & 1 & 1 & 5 & 6 & 1 & 0 & 14 \\
\hline Total & 2 & 1 & 18 & 69 & 228 & 43 & 2 & 361 \\
\hline \multirow[t]{4}{*}{ Age } & $21-30$ & 0 & 1 & 6 & 65 & 5 & 0 & 77 \\
\hline & $31-40$ & 0 & 17 & 41 & 106 & 12 & 1 & 177 \\
\hline & $41-50$ & 0 & 0 & 15 & 39 & 25 & 1 & 80 \\
\hline & $51-60$ & 1 & 0 & 7 & 18 & 1 & 0 & 27 \\
\hline Total & ain & 1 & 18 & 69 & 228 & 43 & 2 & 361 \\
\hline \multirow{3}{*}{$\begin{array}{l}\text { Employment } \\
\text { status } \\
\text { Total } \\
\end{array}$} & Permanent & 1 & 17 & 69 & 223 & 42 & 2 & 354 \\
\hline & Contract & 0 & 1 & 0 & 5 & 1 & 0 & 7 \\
\hline & 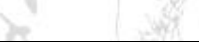 & 1 & 18 & 69 & 228 & 43 & 2 & 361 \\
\hline
\end{tabular}

Sample items included "It satisfies me to do different things from time to time" and "I am motivated because I want to succeed at this job, if not I would be very ashamed of myself". The outcome variable organizational citizenship behavior (OCB) was measured with a 24 items scale given by Podsakoff, MacKenzie, and Podsakoff (2012) with an internal consistency as 0.91. A sample item was "I keep abreast of changes in the organization". Similarly, a 7-items scale from Tynan (2005) was adapted to measure psychological safety (PS), which has been used as moderator in the current study. A sample item was "The boss really cared about me" and "The boss respected my abilities". The initial reliability for PS scale was 0.93 .

The respondents for the current study were employees of the public sector organizations. The study design was cross-sectional where all the data were collected once from a single source (employees only). The initial screening of data was carried out through human observation and missing values were reported back to the participants who were requested to fill the appropriate value wherever applicable. Later on, data were entered into SPSS and the missing values were re-checked through descriptive statistics and frequencies. Since no missing value in the data was found, therefore, was accepted as good for further advanced analysis.

\section{Common Method Bias (CMB)}

According to Podsakoff et al. (2012), due to regular use of the same scales and adopted questionnaires, respondents develop a common response for each of these. The same response repeated over some time 
results in common method bias (CMB). This usually happens due to similarities in measures, scales, items, or wording, etc. Moreover, the data collected from a single source at a single point of time could be exposed to CMB. The research design adopted for the current study was also cross-sectional and could be doubted for the presence of CMB. Tehseen, Ramayah, and Sajilan (2017) have stated that CMB results in elevated numbers or results and poses serious threats to the generalization of the results. To avoid CMB in this research, several procedural measures proposed by Podsakoff et al. (2012) and Tehseen et al. (2017) were adopted. These methods include the assurance for anonymity of the respondents, facilitation with responding to the questionnaire, a cover letter explaining the process and purpose of the study, and focus on practices instead of perceptions, etc. Moreover, the collected data were statistically tested for CMB through Harmen's single factor method. As per Tehseen et al. (2017), if the variance caused by a single factor is more than 50\% then there is a presence of common method bias (CMB) in the collected data which results in elevated numbers. Also, the items will not represent proper responses based on pre-dispositions rather they will represent the responses due to item construction. The results indicated that $32 \%$ of the variance explained by the first factor, which is in an acceptable range (Brannick et al., 2010).

\section{Confirmatory Factor Analysis (CFA)}

Confirmatory Factor Analysis (CFA) confirms the correlations among the items and we checked it using AMOS Version 22. Based on results from the analysis, several items had to be deleted as their factor loadings were less than 0.5 and were creating issues in model fitness. After first order CFA, we found that three dimensions of yoice (SSR, EM, and JS) were strongly correlated with each other. Moreover, the covariance between these three dimensions was also very strong ( $\mathrm{SSR}<-->\mathrm{JS}=0.78 ; \mathrm{SSR}<-->\mathrm{EM}=0.72$; $\mathrm{EM}<-->\mathrm{JS}=0.78$ ). Therefore, we applied second-order CFA which gave better fit indices and also justified the option by indicating very strong factor loadings.

According to Francis and White (2002), the cut-off point adopted should not be less than 0.50. After deleting 31 items, the model fitness improved to the desired level (CMIN/df: $3.303<5$; IFI: $0.972>0.9$; TLI: $0.976>0.9$; CFI: $0.972>0.9$; RMSEA: $0.080 \leq 0.08$, RMR: $0.020 \leq 0.08$ ) and further analysis were carried out on remaining 54 items. The reliability of the instruments was checked through Cronbach alpha, which is used to measure whether the items which have shared covariance can accurately measure the underlying concept. The results generated are mentioned in Table 2. As per Taber (2018), the acceptable range of Cronbach's alpha is from 0.70 to 0.99 . Since the above results indicate an excellent fit, therefore, the constructs were considered reliable as they tend to accurately measure the concept for which they were designed to measure.

To carry out analysis regarding correlation among the constructs, computed variables were used. Correlation depicts the change in magnitude and direction of change in one variable as a result of a change in another variable (Cohen, 1988). The value of correlation, therefore, ranges from -1 to 1 , with -0.8 or more indicating a high negative correlation and 0.8 indicating high level of correlation among the variables with the highest as 0.545 between Voice and OCB and the lowest as 0.375 between PS and OCB. These values are well within the range and indicate that the variables are positively correlated with each other, however since the values are less than 0.70 , the data is not susceptible to multicollinearity.

\section{Results}

To test the hypotheses developed for the current study, Process Macro Model No. 1 was used as recommended by Preacher and Hayes (2004). Table 3 indicates the results of these analyses, where direct relationships between Voice and OCB as well as PS and OCB were checked through multiple regression, and then the interaction effect of PS on the relationship between Voice and OCB was tested. Pearson correlation was calculated for voice, psychological safety, and organizational citizenship behavior Table 2 indicates a moderate to a high positive correlation with $\mathrm{p}<0.01$. 
Table 2. Reliability and Validity Analyses

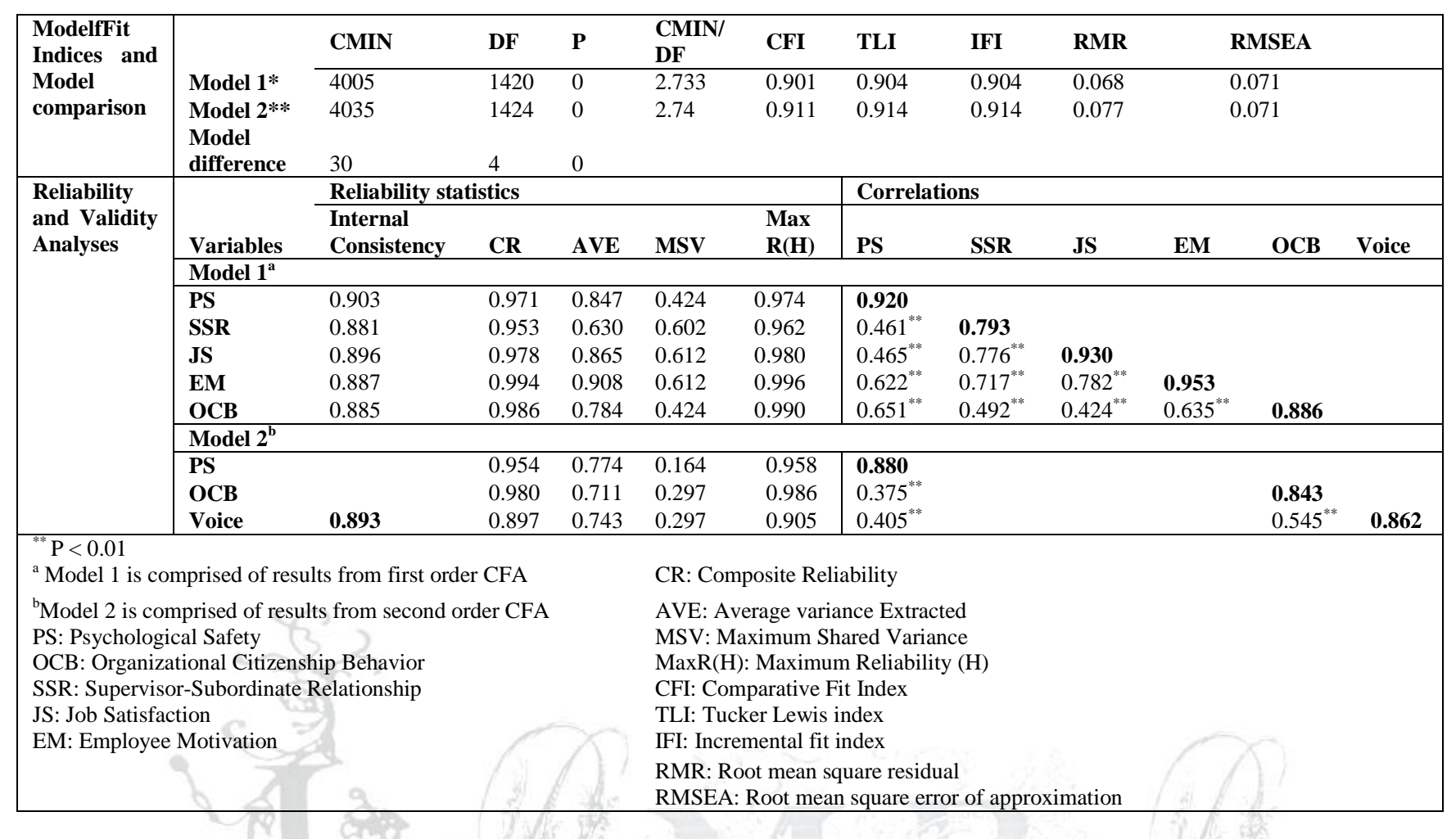

Table 3 - Regression estimates

\begin{tabular}{|l|ccc|c|cc|}
\hline Model & $\begin{array}{c}\text { Sum of } \\
\text { Squares }\end{array}$ & Df & $\begin{array}{c}\text { Mean } \\
\text { Square }\end{array}$ & F & R & $\mathbf{R}^{\mathbf{2}}$ \\
\hline Regression & 486.808 & 1 & 486.808 & $1198.94^{* *}$ & $0.450^{* *}$ & $0.203^{* *}$ \\
Residual & 145.766 & 359 & 0.406 & & \\
Total & 632.574 & 360 & SE & T \\
\hline \multicolumn{7}{c}{ Coefficient } \\
\hline Constant & $1.1091^{* *}$ & 0.174 & 6.3743 \\
Voice(X) & $0.2399^{*}$ & 0.1006 & 2.3838 \\
PS(W) & $0.1281^{*}$ & 0.0586 & 2.1851 \\
Int_1 & $0.0861^{* *}$ & 0.0247 & 3.4799 \\
\hline
\end{tabular}

Note: $* *=\mathrm{p}<0.01 ; *=\mathrm{p}<0.05$

Table I indicates the fitness of the research model as satisfactory ( $F=1198.4, p<0.001)$, and the $\mathrm{R}^{2}$ explains $20.3 \%$ of the overall variance. The results also indicate that the relationship among voice $(b=0.24, p<0.05)$, psychological safety $(b=0.128, p<0.05)$, and organizational citizenship behavior were positive and significant. The interaction effect reflects a positive moderation of PS on the relationship between voice and OCB. In this case, the effect was observed as 0.0861 with significant $T$ statistics (T: $3.48, \mathrm{p}<0.001$ ). These results indicate that employees exhibit significant increases (b: $0.0861, \mathrm{p}<0.001$ ) in their organizational citizenship behavior if they are given the opportunity to raise their voice in the presence of psychological safety. The interaction was further verified through the conditional effects of voice on OCB at various levels of PS. As shown in Table 4, with an increase in the level of psychological capital the effect of voice on OCB also increases. Figure 2 reflects the visual depiction of the interaction effect, plotted 
in MS Excel. It clearly indicates that with the increased value of PS, the OCB goes up. In other words, keeping voice constant, there is a positive effect of PS on OCB.

Table 4 - Conditional interaction effect

\begin{tabular}{|cccc|}
\hline PS & Effect & SE & T \\
\hline 2.0000 & $.412^{* * *}$ & .055 & 7.49 \\
4.0000 & $.584 * * *$ & .029 & 20.31 \\
4.7500 & $.649 * * *$ & .036 & 18.24 \\
\hline
\end{tabular}

Note: $* * *=p<0.001$

Predictor: Voice

Dependent variable: $O C B$

Figure 3 - Interaction Effect

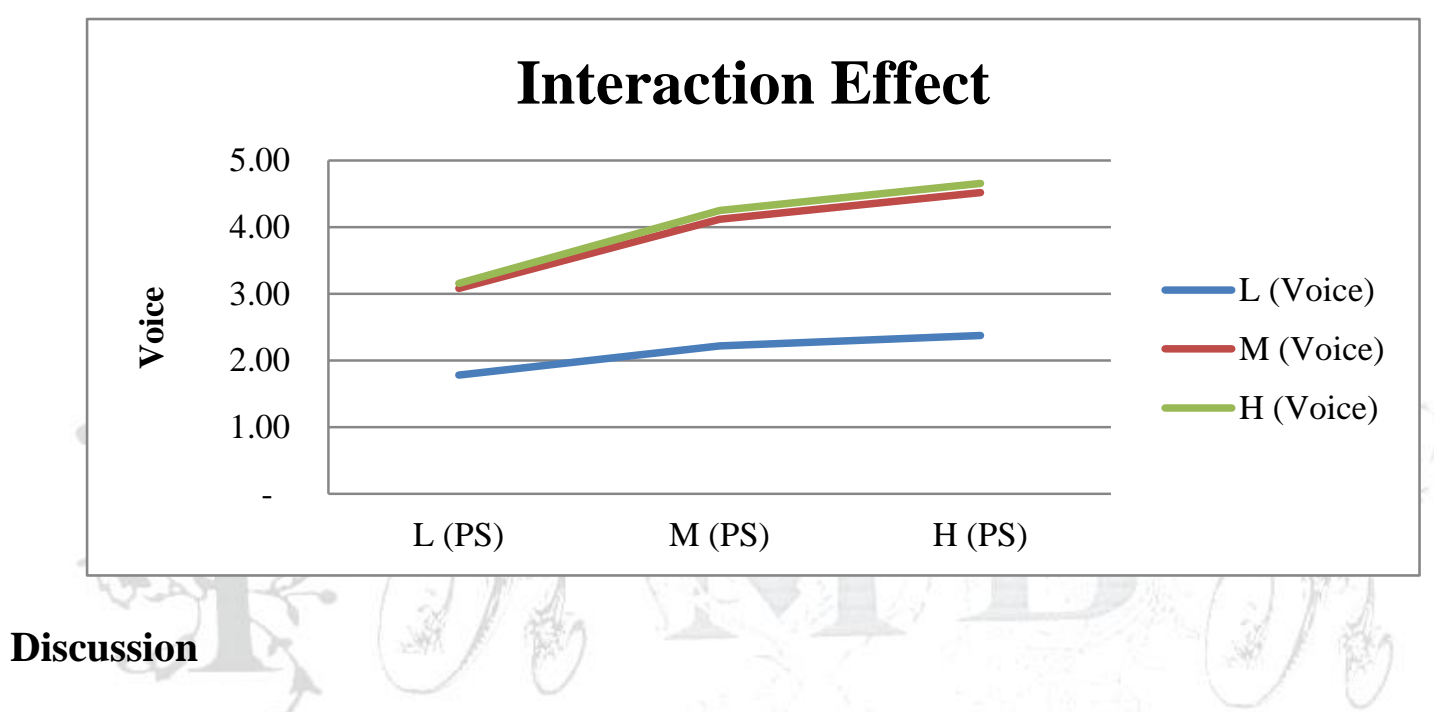

The study aimed to investigate the relationship between employee voice and organizational citizenship behavior, in the presence of psychological safety as a moderator. Based on results and analysis, it can be concluded that the employee voice significantly predicts the organizational citizenship behavior in public sector organizations. Therefore, we accept the H1 as true in the current study.

Another dimension of the research was to study the relationship between psychological safety and organizational citizenship behavior. The result provided evidence that psychological safety has a significant and positive effect on organizational citizenship behavior (Basit 2017; Edmondson \& Lei, 2014). Previously, researchers tested this relationship in different scenarios and relationships. Therefore, they provided different views in each case and did not exactly match the current findings (Leroy et al., 2012; Hetzner et al., 2011). However, we had hypothesized that there would be a positive and significant relationship between PS and OCB, which stands accepted. The results further indicate that psychological safety significantly moderates the relationship between organizational voice and organizational citizenship behavior. Previously, most researchers have studied the psychological safety as a mediating variable with organizational citizenship behavior (Morrison, 2011). In our study, it was examined as a moderator and proved significantly effective in increasing the strength of the relationship between voice and OCB. These results provided evidence to accept the third hypothesis as true.

The current research has supported the findings of many other studies conducted to determine either the dimensions of organizational voice or the relationship between voice and organizational citizenship behavior. But most previous research considered one of the dimensions and established relationships in 
different contexts. For instance, Suer and Kecici (2018) concluded that as a result of a good supervisorsubordinate relationship, the employees tend to be more positive and their behavior towards the organization becomes better. This study has also concluded that if supervisors provide a conducive and friendly work environment, employees feel encouraged to raise their voices. This type of voice behavior leads to improvement in their organizational citizenship behavior within the organization.

As per previous research, the organizational voice was measured through its dimensions, however, what specific factors contributed to measuring organizational voice were less known (Morrison, 2014). The issue was accordingly addressed by James and Moseley (2014) who concluded that voice as a latent variable could be measured by the supervisor-subordinate relationship. Similarly, several studies have concluded that different dimensions of employee voice could be used to measure voice effectively (Weiss et al., 2017; Barry and Wilkinson, 2016; Schmitt et al., 2016; Hassan et al., 2015; Rasheed et al., 2017).

Another aspect studied by this research was the moderating role of psychological safety on the relationship between organizational voice and organizational citizenship behavior. This study provided evidence that psychological safety positively moderates the relationship between organizational voice and organizational citizenship behavior. In other words, if employees feel safe to raise their concerns and issues about procedures and work processes of the organization, they feel themselves a productive part of the organization and participate enthusiastically. This will increase their voice behavior and they would be more open to giving their innovative ideas or opinions to improve the organizational functioning. Resultantly their level of commitment and citizenship behavior with the organization will improve. However, some previous researchers have used PS as a mediator. Basit (2017) concluded that there is a mediating role of psychological safety between organizational voice and organizational citizenship behavior. However, the current study supported and proved its moderation role that increases the intensity of the relationship between voice and OCB. Similar conclusions were drawn by Edmondson and Lei (2014) as well. They concluded that whenever employees in an organization feel that they are psychologically secure, they tend to increase voice behavior and also organizational citizenship behavior. It is, therefore, safe to infer that psychological safety positively moderates the relationship between organizational voice and organizational citizenship behavior.

\section{Implications and Future Research}

The power distance between supervisors and subordinates and the cultural differences play a critical role in creating and encouraging voice behavior among employees. The current study has authenticated that there is a positive relationship among supervisor-subordinate relationship and voice behavior; however, power distance has not been taken as another dimension or factor leading to voice behavior. Pakistani bureaucratic culture is characterized by a fairly high-power distance. Therefore, we strongly felt the need to include power distance as another important factor of voice behavior, which can be studied in the future (Son, 2019). Moreover, some other dimensions can also have potential effects on voicing behavior like organizational culture, employees' personality type, etc. which can be considered in future studies. A comparative study of different sectors (private, public, service, manufacturing, etc.) can provide a better explanation of the fundamentals of voicing behavior and its consequences. Over time, several other aspects of voice such as egoistic voice and respectful voice have also emerged, which can be studied. Also, the industry can be changed with an emphasis on supervisor and subordinate related voice in the corporate sector (Tan et al., 2019).

Data for the current study were collected from a single source at one point in time. This type of data could be disposed to potential Common Method Bias (CMB). Although we used multiple measures to control CMB like protection of confidentiality, assurance on academic use of information, assistance in filling the questionnaire, etc., still more rigorous procedural and statistical methods were required (Podsakoff et al., 2003). These include data from multiple sources, temporal separation of measurement, dyadic research 
design, pre-post or longitudinal research designs, etc. Future research can adopt these strategies to reduce $\mathrm{CMB}$ and increase validity as well as the generalizability of results.

\section{Contribution of the Research}

This study is unique as it adds to the literature several new aspects such as the direct and moderating impact of psychological safety on organizational citizenship behavior in the public sector of Pakistan. This study further reinforces the findings of earlier research conducted to analyze the concept of organizational voice and its measurement through supervisor-subordinate relationships, employee job satisfaction, and employee motivation. Especially we have revalidated the social exchange theory which explains the social behavior of two parties involved in mutual interaction. The theory postulates that the interaction between two parties is dependent on cost-effectiveness and risks benefit analysis, involved in mutual communication. The current study has proved that employees determine the extent of raising voice based on their relationship with their supervisor. Better relationships between two parties give them the confidence to raise their voice for the betterment of their organization. Moreover, the strength of this relationship increases if employees feel it safe to speak. This kind of conducive environment enhances their citizenship behavior with their organization. This study will help other researchers to see voice behavior in public sector organizations of Pakistan. This research has added to the existing literature by suggesting the ways and means through which the organizational voice could be promoted. Moreover, the moderating role of psychological safety on the relationship between voice and OCB is an addition to the body of knowledge. Likewise, we also provide useful suggestions to address the critical organizational problems relating to employee citizenship behavior. These suggestions include improving the supervisor-subordinate relationship, motivating employees, improving their satisfaction with their work, and ensuring a psychologically safe environment to raise their voice for the betterment of the organizational processes and procedures. Employee voice behavior is critical as they directly deal with critical procedural constraints and can provide innovative ideas and solutions based on ground realities.

\section{Conclusion}

This study investigated the relationship between employee voice and organizational citizenship behavior with the moderating role of psychological safety. We found that employees' voice positively contributes to organizational citizenship behavior. Furthermore, psychological safety moderates the relationship between employee voice and organizational citizenship behavior in the public sector organizations of Pakistan.

\section{References}

Adegbaju, O. (2018). Employee engagement in a collectivist high power distance culture. Aston University.

Alfayad, Z. \& Arif, L. S. M. (2017). Employee voice and job satisfaction: An application of Herzberg twofactor theory. International Review of Management and Marketing, 7(1), 150-156.

Aryee, S., Walumbwa, F. O., Mondejar, R. \& Chu, C. W. (2017). Core self-evaluations and employee voice behavior: Test of a dual-motivational pathway. Journal of Management, 43(3), 946-966.

Ashford, S. J., Sutcliffe, K. M. \& Christianson, M. K. (2009). Speaking up and speaking out: The leadership dynamics of voice in organizations. Voice and Silence in Organizations, 175-202.

Avey, J. B., Wernsing, T. S., \& Palanski, M. E. (2012). Exploring the process of ethical leadership: The mediating role of employee voice and psychological ownership. Journal of Business Ethics, 107(1), 21-34.

Barry, M. \& Wilkinson, A. (2016). Pro-social or pro-management? A critique of the conception of employee voice as a pro-social Behavior within organizational Behavior. British Journal of Industrial Relations, 54(2), 261-284.

Bashshur, M. R. \& Oc, B. (2015). When voice matters: A multilevel review of the impact of voice in organizations. Journal of Management, 41(5), 1530-1554. 
Basit, A. A. (2017). Trust in Supervisor and Job Engagement: Mediating Effects of Psychological Safety and Felt Obligation. The Journal of psychology, 151(8), 701-721.

Beheshtifar, M., Borhani, H. \& Moghadam, M. N. (2012). Destructive role of employee silence in organizational success. International Journal of Academic Research in Business and Social Sciences, 2(11), 275.

Berger, C. (2009). Communication: A goal-directed, plan-guided process. In Communication and social cognition (pp. 59-82). Routledge.

Bienefeld, N. \& Grote, G. (2012). Silence that may kill. Aviation Psychology and Applied Human Factors.

Botero, I. C. \& Dyne, L. (2009). Employee voice behavior: Interactive effects of LMX and power distance in the United States and Colombia. Management Communication Quarterly, 23(1), 84-104.

Brannick, M. T., Chan, D., Conway, J. M., Lance, C. E. \& Spector, P. E. (2010). What is method variance and how can we cope with it? A panel discussion. Organizational Research Methods, 13(3), 407-420.

Budd, J. W., Gollan, P. J. \& Wilkinson, A. (2010). New approaches to employee voice and participation in organizations. Human Relations, 63(3), 303-310.

Chan, S. H. J., \& Lai, H. Y. I. (2017). Understanding the link between communication satisfaction, perceived justice and organizational citizenship behavior. Journal of Business Research, 70, 214-223.

Chen, S. C. (2017). Paternalistic leadership and cabin crews' upward safety communication: The motivation of voice behavior. Journal of Air Transport Management, 62, 44-53.

Cheng, J., Lu, K., Chang, Y. \& Johnstone, S. (2013). Voice behavior and work engagement: the moderating role of supervisor-attributed motives. Asia Pacific Journal of Human Resources, 51(1), 81-102.

Chrobot-Mason, D., \& Aramovich, N. (2004). Employee perceptions of an affirming climate for diversity and its link to attitudinal outcomes: A comparison of racial and gender groups. Annual Meeting of the Academy of Management, New Orleans, LA.

Cinar, O., Karcıoğlu, F. \& Alioğulları, Z. D. (2013). The relationship between organizational silence and organizational citizenship behavior: A survey study in the province of Erzurum, Turkey. ProcediaSocial and Behavioral Sciences, 99, 314-321.

Cohen, J. (1988). Statistical Power Analysis for the Behavioral Sciences. Academic Press, New York, 2nd edn.

Deci, E. L. \& Ryan, R. M. (2000). The" what" and" why" of goal pursuits: Human needs and the selfdetermination of behavior. Psychological inquiry, 11(4), 227-268.

Dekas, K. H., Bauer, T. N., Welle, B., Kurkoski, J. and Sullivan, S. (2013). Organizational citizenship behavior, version 2.0: A review and qualitative investigation of OCBs for knowledge workers at Google and beyond. The Academy of Management Perspectives, 27,219-237.

Detert, J. R. and Burris, E. R. (2007). Leadership behavior and employee voice: Is the door really open? Academy of Management Journal, 50, 869-884.

Dutton, J. E., Ashford, S. J., O'Neill, R. M. and Lawrence, K. A. (2001). Moves that matter: Issue selling and organizational change. Academy of Management Journal, 44(4), 716- 736.

Edmondson, A. C. (1999). Psychological safety and learning behavior in work teams. Administrative Science Quarterly, 44, 350-383

Farndale, E., Van Ruiten, J., Kelliher, C. \& Hope-Hailey, V. (2011). The influence of perceived employee voice on organizational commitment: An exchange perspective. Human Resource Management, 50(1), 113-129.

Edmondson, A. C. \& Lei, Z. (2014). Psychological safety: The history, renaissance, and future of an interpersonal construct. Annu. Rev. Organ. Psychol. Organ. Behav, 1(1), 23-43.

Fast, N. J., Burris, E. R. \& Bartel, C. A. (2014). Managing to stay in the dark: Managerial self-efficacy, ego defensiveness, and the aversion to employee voice. Academy of Management Journal, 57(4), 10131034.

Fatima, A., Salah-Ud-Din, S., Khan, S., Hassan, M. \& Hoti, H. A. K. (2015). Impact of organizational silence on organizational citizenship behavior: Moderating role of procedural justice. Journal of Economics, Business and Management, 3(9), 846-850.

Frandsen, F. \& Johansen, W. (2018). Voices in conflict? The crisis communication of meta-organizations. Management Communication Quarterly, 32(1), 90-120. 
Frazier, M. L. \& Bowler, W. M. (2015). Voice climate, supervisor undermining, and work outcomes: A group-level examination. Journal of Management, 41(3), 841-863.

Garner, J. T. \& Garner, L. T. (2011). Volunteering an opinion: Organizational voice and volunteer retention in nonprofit organizations. Nonprofit and Voluntary Sector Quarterly, 40(5), 813-828.

Grant, A. M. \& Mayer, D. M. (2009). Good soldiers and good actors: Prosocial and impression management motives as interactive predictors of affiliative citizenship behaviors. Journal of Applied Psychology, 94(4), $900-912$.

Hassan, M. U., Hassan, I. E. \& Batool, F. (2015). Employee voice Behavior in organizations: evidence from Pakistan. Asian Journal of Management Science and Applications, 2(2), 195-212.

Heffernan, M. \& Dundon, T. (2015). The role of front line managers in employee voice: a social exchange perspective.

Hetzner, S., Gartmeier, M., Heid, H. \& Gruber, H. (2011). Error orientation and reflection at work. Vocations and Learning, 4, 25-39.

Hirschfeld, R. R. (2000). Does revising the intrinsic and extrinsic subscales of the Minnesota Satisfaction Questionnaire short form make a difference? Educational and Psychological Measurement, 60(2), 255-270.

Hirschman, A. O. (1970). Exit, voice, and loyalty: Responses to decline in firms, organizations, and states (Vol. 25). Harvard university press.

Ho, J.C., (2017). The Effect of Supervisor Support on Employee Voice Behavior based on the SelfDetermination Theory: The Moderating Effect of Impression Management Motive. J Entrepren Organiz Manag, 6, 209.

Hober, B., Schaarschmidt, M., \& von Korflesch, H. (2019). Internal idea contests: Work environment perceptions and the moderating role of power distance. Journal of Innovation \& Knowledge.

Hoti, K., Sandhu, J., Satti, A., Jamil, M., Rukhsana.,Abbasi, Q. \& Wajid, (2016). Annual Statistical Bulletin of Federal Government Employees 2014-2015.

Hunjra, A. I., Ali, M. A., Chani, D., Irfan, M., Khan, H. \& Rehman, K. U. (2010). Employee voice and intent to leave: An empirical evidence of Pakistani banking sector. African Journal of Business Management, 4(14), 3056-3061.

Jaffery, H. (2014). Mediation of psychological capital between organizational climate and organizational citizenship behavior. Pakistan Journal of Commerce and Social Sciences, 8(2), 453-470.

Jain, A. K., Giga, S. I. \& Cooper, C. L. (2011). Social power as a means of increasing person and organizational effectiveness: The mediating role of organizational citizenship Behavior. Journal of Management and Organization, 17, 412-432.

James, O. \& Moseley, A. (2014). Does performance information about public services affect citizens' perceptions, satisfaction, and voice Behavior? Field experiments with absolute and relative performance information. Public Administration, 92(2), 493-511.

Janssen, O. \& Gao, L. (2015). Supervisory responsiveness and employee self-perceived status and voice behavior. Journal of Management, 41, 1854-1872.

Jha, N., Potnuru, R. K. G., Sareen, P. \& Shaju, S. (2019). Employee voice, engagement and organizational effectiveness: a mediated model. European Journal of Training and Development.

Kalia, S. (2013). Bureaucratic Policy Making in Pakistan. Dialogue (Pakistan), 8(2).

Kandlousi, N. S. A. E., Ali, A. J., \& Abdollahi, A. (2010). Organizational citizenship behavior in concern of communication satisfaction: The role of the formal and informal communication. International Journal of Business and Management, 5(10), 51.

Kim, M., Knutson, B.J. \& Choi, L. (2015). The effects of employee voice and delight on job satisfaction and behaviors: comparison between employee generations. Journal of hospitality marketing and management, 00, 1-26.

Lam, C. F., Rees, L., Levesque, L. L. \& Ornstein, S. (2018). Shooting from the hip: A habit perspective of voice. Academy of Management Review, 43(3), 470-486.

Lapointe, É., \& Vandenberghe, C. (2018). Examination of the relationships between servant leadership, organizational commitment, and voice and antisocial behaviors. Journal of Business Ethics, 148(1), 99-115. 
Leroy, H., Dierynck, B., Anseel, F., Simons, T., Halbesleben, J. R., McCaughey, D. \& Sels, L. (2012). Behavioral integrity for safety, priority of safety, psychological safety, and patient safety: A team-level study. Journal of Applied Psychology, 97(6), 1273.

Li, N., \& Yan, J. (2007). The mechanism of how trust climate impacts on individual performance. Acta Psychologica Sinica, 39(06), 1111-1121.

Li, R., \& Ling, W. (2010). The Impact of Perceived Supervisor Support on Employees' Work-related Attitudes and Silence Behavior. Journal of Business Economics, 5(007).

Liang, J., Farh, C. I. C. and Farh, J.-L. (2012). Psychological antecedents of promotive and prohibitive voice: A two-wave examination. Academy of Management Journal, 55(1), 71-92.

Lin, X., Chen, Z. X., Herman, H. M., Wei, W., \& Ma, C. (2019). Why and when employees like to speak up more under humble leaders? The roles of personal sense of power and power distance. Journal of Business Ethics, 158(4), 937-950.

Ling, Y., \& Zeyin, L. (2016). The Relationship Between Organizational Ethical Climate and Employee Voice Behavior under the Perspective of Psychological Safety. Human Resources Development of China, (5), 9.

Ma, C. (2016). The role of approach and avoidance motivation in employee voice: The moderating effect of ostracism and contingent self-esteem. International Journal of Productivity and Performance Management, 65(6), 744-759.

Macdonald, S. \& Maclntyre, P. (1997). The generic job satisfaction scale: Scale development and its correlates. Employee Assistance Quarterly, 13(2), 1-16.

Miao, R., Lu, L., Cao, Y., \& Du, Q. (2020). The High-Performance Work System, Employee Voice, and Innovative Behavior: The Moderating Role of Psychological Safety. International Journal of Environmental Research and Public Health, 17(4), 1150.

Milliken, F. J., Schipani, C. A., Bishara, N. D. \& Prado, A. M. (2015). Linking workplace practices to community engagement: The case for encouraging employee voice. Academy of Management Perspectives, 29(4), 405-421.

Milosevic, J. M. (2017). Shared Leadership: Enactment, Perception, and the Role of Power Distance.

Ming, C., Xiaoying, G., Huizhen, Z., \& Bin, R. (2015). A review on psychological safety: Concepts, measurements, antecedents and consequences variables. 2015 International Conference on Social Science and Technology Education. Atlantis Press.

Morrison, E. W. (2011). Employee voice behavior: Integration and directions for future research. Academy of Management annals, 5(1), 373-412.

Morrison, E. W. (2014). Employee voice and silence. Annu. Rev. Organ. Psychol. Organ. Behav., 1(1), 173-197.

Mulhern, F. \& Massey, J. (2013). Motivation and satisfaction among public sector employees. The Forum of Business Results Through People, Northwestern University, Available at:(Http://Www. Marketing. Org/Files/Employee\% 20Engagement\% 20for\% 20Public\% 20Sector_-WTrusteeList. Pdf.

Nechanska, E., Hughes, E., \& Dundon, T. (2020). Towards an integration of employee voice and silence. Human Resource Management Review, 30(1).

Nembhard, I. M. \& Edmondson, A. C. (2011). Psychological safety: A foundation for speaking up, collaboration, and experimentation. In K. S. Cameron and G. M. Spreitzer (Eds.), The Oxford handbook of positive organizational scholarship. Oxford: Oxford University Press.

Newman, A., Donohue, R. \& Eva, N. (2017). Psychological safety: A systematic review of the literature. Human Resource Management Review, 27(3), 521-535.

$\mathrm{Ng}, \mathrm{T}$. W. and Feldman, D. C. (2015). Idiosyncratic deals and voice behavior. Journal of Management, 41(3), 893-928.

Ohana, M. (2016). Voice, affective commitment and citizenship behavior in teams: The moderating role of neuroticism and intrinsic motivation. British Journal of Management, 27(1), 97-115.

Oreg, S., Bartunek, J. M., Lee, G. \& Do, B. (2018). An affect-based model of recipients' responses to organizational change events. Academy of Management Review, 43(1), 65-86.

Organ, D. W. (1988). A restatement of the satisfaction-performance hypothesis. Journal of management, 14(4), 547-557. 
Pierce, H. R. \& Maurer, T. J. (2009). Linking employee development activity, social exchange and organizational citizenship behavior. International Journal of Training and Development, 13, 139-147.

Podsakoff, P. M., MacKenzie, S. B. \& Podsakoff, N. P. (2012). Sources of method bias in social science research and recommendations on how to control it. Annual review of psychology, 63, 539-569.

Pyman, A., Cooper, B., Teicher, J. \& Holland, P. (2006). A comparison of the effectiveness of employee voice arrangements in Australia. Industrial Relations Journal, 37(5), 543-559.

Qi, Y. and Ming-Xia, L. (2014). Ethical leadership, organizational identification and employee voice: Examining moderated mediation process in the Chinese insurance industry. Asia Pacific Business Review, 20(2), 231-248.

Rasheed, M. A., Shahzad, K., Conroy, C., Nadeem, S. \& Siddique, M. U. (2017). Exploring the role of employee voice between high-performance work system and organizational innovation in small and medium enterprises. Journal of Small Business and Enterprise Development.

Ruck, K., Welch, M. \& Menara, B. (2017). Employee voice: An antecedent to organisational engagement? Public Relations Review, 43(5), 904-914.

Scarpello, V. \& Vandenberg, R. J. (1987). The satisfaction with my supervisor scale: Its utility for research and practical applications. Journal of Management, 13(3), 447-466.

Schmitt, A., Den Hartog, D. N. \& Belschak, F. D. (2016). Transformational leadership and proactive work Behavior: A moderated mediation model including work engagement and job strain. Journal of occupational and organizational psychology, 89(3), 588-610.

Singh, B., Winkel, D. E., \& Selvarajan, T. T. (2013). Managing diversity at work: Does psychological safety hold the key to racial differences in employee performance? Journal of Occupational and Organizational Psychology, 86(2), 242-263.

Song, J., He, C., Wu, W. \& Zhai, X. (2018). Roles of self-efficacy and transformational leadership in explaining voice-job satisfaction relationship. Current Psychology, 1-12.

Spitzmuller, M., Van Dyne, L., \& Ilies, R. (2008). Organizational citizenship behavior: A review and extension of its nomological network. The SAGE Handbook of Organizational Behavior, 1, 106-123.

Suer, F. C. \& Keçeci, M., (2018). The moderating effect of supervisory responsiveness on the relationship between leader member exchange quality and voice behavior. International Journal of Social Science $66,433-445$.

Taber, K. S. (2018). The use of Cronbach's alpha when developing and reporting research instruments in science education. Research in Science Education, 48(6), 1273-1296.

Tangirala, S. \& Ramanujam, R. (2008). Exploring nonlinearity in employee voice: The effects of personal control and organizational identification. Academy of Management Journal, 51(6), 1189-1203.

Tehseen, S., Ramayah, T. \& Sajilan, S. (2017). Testing and controlling for common method variance: a review of available methods. Journal of Management Sciences, 4(2), 142-168.

Tynan, R. (2005). The Effects of Threat Sensitivity and Face Giving on Dyadic Psychological Safety and Upward Communication, Journal of Applied Social Psychology, 35(2), 223-247.

Walumbwa, F. O., \& Schaubroeck, J. (2009). Leader personality traits and employee voice behavior: mediating roles of ethical leadership and work group psychological safety. Journal of Applied Psychology, 94(5), 1275.

Wang, Y., \& Lin, L. (2019). Research on the Influence of New Generation Employees' Work Values on Employee Voice Behavior. 1st International Conference on Business, Economics, Management Science (BEMS 2019). Atlantis Press.

Weiss, M., Kolbe, M., Grote, G., Spahn, D. R. \& Grande, B. (2017). Why didn't you say something? Effects of after-event reviews on voice Behavior and hierarchy beliefs in multi-professional action teams. European Journal of Work and Organizational Psychology, 26(1), 66-80.

Whiting, S. W., Podsakoff, P. M. \& Pierce, J. R. (2008). Effects of task performance, helping, voice, and organizational loyalty on performance appraisal ratings. Journal of Applied Psychology, 93(1), 125.

Wu, W.-K., Wang, W., Liu, J., \& Wu, L. Z. (2012). Abusive supervision, perceived psychological safety and voice behavior. Chinese Journal of Management, 9(1), 57-63. 